\title{
STUDENT SELF-DETERMINATION AND BOUNDARIES: AN EMERGING MARKET PERSPECTIVE ON THE DEVELOPMENT OF SALES SKILLS
}

\section{Wait*}

https://orcid.org/0000-0001-6438-5956

\section{B. Stiehler*}

http://orcid.org/0000-0001-9342-4977

*Department: Marketing Management

University of Johannesburg

Johannesburg, South Africa

\section{ABSTRACT}

In an emerging market economy faced with high unemployment rates, it is essential to develop entrepreneurial skills, of which sales skills have been identified as an imperative contributor. Applying self-determination theory and boundary theory, this study explores what motivates students enrolled in a direct selling practical module at a university to pass the module successfully in the form of reaching a sales target. It also explores the boundaries that students assign between their student and personal lives, and their perception of the skills they have developed on completion of the module. The research approach was qualitative and employed eight in-depth interviews. Inductive content analysis was used to analyse the data. The findings revealed enacted segmentation as students distinguish between their life/home and work/school roles, but are constantly aware of the module. It was also found that the students believe the module made a positive contribution to the development of several skills. The findings contribute on two levels: practically, it may aid educators who offer similar courses, or who operate in countries with similar challenges, with insights on how to improve their sales courses; and theoretically, it contributes to the development of theories applicable to emerging economies.

Keywords: direct selling, sales education, emerging economy, sales skills, self-determination theory, boundary theory

\section{INTRODUCTION}

The emerging market of South Africa faces a number of challenges, including an unemployment rate of 29.1 per cent (StatsSA 2019), high levels of poverty and inequality, poor healthcare, insufficient energy supplies, and crime and corruption. Poverty and inequality, followed by high unemployment rates, are the most prominent of these challenges. In addressing these, the South African government has embarked on numerous initiatives, with 
investment in higher education studies and the encouragement of entrepreneurship having received a lot of attention (Aucamp 2015; Chimucheka 2014; Entrepreneurship Development in Higher Education [EDHE] 2018; Urban 2018; Walwyn 2016).

Investment in higher education institutions (universities) has been identified as an important way to help overcome highly unequal societies (Hornsby 2015), resulting in the South African government investing heavily in promoting student enrolment at universities. This investment resulted in considerable growth in students' enrolments at universities in recent years, and is expected to increase substantially in the future (Nkomo 2015; Mabelebele 2015; Malele 2011; Mushemeza 2016; Walwyn 2016).

Compared with their Western counterparts, South African universities face a unique set of challenges when it comes to their students. Funding is by far the most prevalent problem, followed by the pressure to support a great number of students coming from disadvantaged backgrounds (often from a rural community) to adapt to a new environment and to pass and complete their degrees successfully (Dell 2018; Nkomo 2015; Strydom 2016; Waghid and Davis 2016). Therefore, South African universities not only act as a boy for knowledge generation, but are also an important constituent of society (Strydom 2016).

Apart from the increase in student intake at universities, the government drive to increase entrepreneurship has also impacted these institutions (Chimucheka 2014; EDHE 2018; Radipere 2012) and has become a prime way to relieve unemployment and poverty. However, the challenge is for universities to stop producing entrepreneurial graduates and to produce entrepreneurs, regardless of what they study (Radipere 2012). Some of the essential skills for entrepreneurs are marketing and sales (Anderson, Chandy, and Zia 2018). Anderson et al. (2018) discovered that entrepreneurs with sales and marketing skills have a higher success rate in achieving business growth. Consequently, developing marketing and sales skills among graduates may serve as an important contributor to producing future entrepreneurs who can achieve business growth and, in turn, address the country's pressing challenges.

One such initiative currently in place at one of South Africa's largest teaching universities is a direct selling module, in collaboration with the Direct Selling Association (DSA) of South Africa. This is a work-integrated learning (WIL) module that challenges students to reach a specified sales target in order to pass the module, while also making extra money as the commission/rebates earned on sales made are for the students' own pockets. Nevertheless, the module has a 20 per cent failure rate and is met with varying levels of student enthusiasm. Some students embrace it, while others merely aim to pass the module. However, the challenge is that South African students often face more than just worries about their studies. As stated, funding is a major concern (Dell 2018; Nkomo 2015; Strydom 2016; Waghid and Davis 2016); many 
students try to manage part-time work alongside their studies; their accommodation situations are often challenging; many eat unhealthily, as they cannot afford proper meals; and some still try to support their families while studying (Dison, Shalem, and Langsford, 2019; DominguezWhitehead 2017).

Because sales is argued to be a core skill that entrepreneurs need help to develop (Anderson et al. 2018; Forbes Coaches Council 2018), and against the background of the difficulties that South African students face, this study seeks to understand the daily lives, routines, and challenges of the students enrolled in this specific module, and what motivates them to pass it. Insights gained can be applied for better comprehension of how this module could be offered and managed and, potentially, adjusted to ensure that these essential skills are adequately developed. These insights may also serve as inputs to other sales educators who are faced with similar student challenges and conditions. In addressing the aim of this study, this study further seeks to extend the theories of self-determination (Deci and Ryan 1985) and boundary spanning (Schrank 2006), and draws on these theories to address the following objectives:

- to understand what motivates students to pass the direct selling module by applying the self-determination theory (SDT) continuum;

- to discover how students manage their school and personal responsibilities and challenges while enrolled in this sales module by applying the boundary theory to identify whether they engage in enacted integration or enacted segmentation; and

- to discover what knowledge the students manage to retain and apply from the module, and whether the acquisition of this knowledge adds value to their lives.

\section{LITERATURE REVIEW}

This section endeavours to set the scene wherein the WIL project takes place. The students in this project must pass this module and have to adopt specific motivations and set boundaries in which to operate. The literature review reflects on the SDT and boundary theories as possible frameworks wherein the student does practical selling. It is worth mentioning that these two theories were developed in the US, a developed economy, and applied in South Africa, an emerging economy.

\section{The direct selling project}

The direct selling module, in collaboration with the DSA of South Africa as an industry partner, 
has been running since 2002, and is known as the "DSA-UJ Project". The DSA of South Africa (2020), although self-regulating, is the umbrella body, who direct selling companies have membership to. Currently, there are 31 member companies. Three of these companies - namely Tupperware, Table Charm, and Avon Justine - were involved in the 2019 DSA Project.

Firstly, to prepare the students for the project, they are classroom taught and provided with academic knowledge of personal selling and sales management. Thereafter, they must sign up with one of the project's DSA companies and is expected to apply the academic knowledge in the real world and reach a predetermined sales target.

Members of the participating companies interact with the students on the university campus every Friday, and receive further training by the companies on their products. The DSA-UJ Project is a stand-alone year module where-in students pass or fail depending on whether they reach this predetermined sales target. The project evaluates the students' practical sales skills, and the students earn commission while they are making sales. More sales result in more commission, for example, on a sales target of R10 000 (+/- \$700), a student earns R2 500 $(+/-\$ 200)$ commission. This project is very focused on assisting with socio-economic development and the development of entrepreneurial skills as part of the greater drive to develop entrepreneurs in a challenging economic environment.

As this module has been met with varying levels of student drive and pass rates, the authors identified the need to gain a better understanding of what motivates the students. The authors also recognised the theory of self-determination as suitable to aid in identifying the varying levels of drive and ways of thinking to discover what motivates students to pass this module. The boundary theory was applied to establish if the students recognise a clear distinction between their student and personal lives.

\section{Self-determination theory}

SDT evolved from research conducted on intrinsic motivation during the 1970s (Deci 1971; Lepper, Green, and Nisbet 1973), but was only introduced and accepted as a theory in the mid 1980s (Deci and Ryan 1985). The SDT extended the cognitive evaluation theory (CET) and addressed some of the criticism of that and earlier theories by applying a segregated analysis of extrinsic motivation. SDT proposed the process of internalisation, specifically suggesting that extrinsic motivation can be internalised and autonomous. The theory focuses on people's evolved inner resources of their personality and self-regulation behavioural systems, and argues that extrinsic motivation can become internalised and eventually be autonomously regulated (Deci and Ryan 2000). The theory also proposes that contentment of the needs for competence, relatedness, and autonomy are key elements of autonomous behaviour (Gagné and Deci 2005). 
Therefore, people who experience higher levels of satisfaction of these needs have a higher likelihood of belonging to an autonomous motivational profile. However, conditions that encourage these positive processes to occur are required (Deci and Ryan 2000).

Table 1: Graphical representation of the SDT (Source: Deci and Ryan 1985)

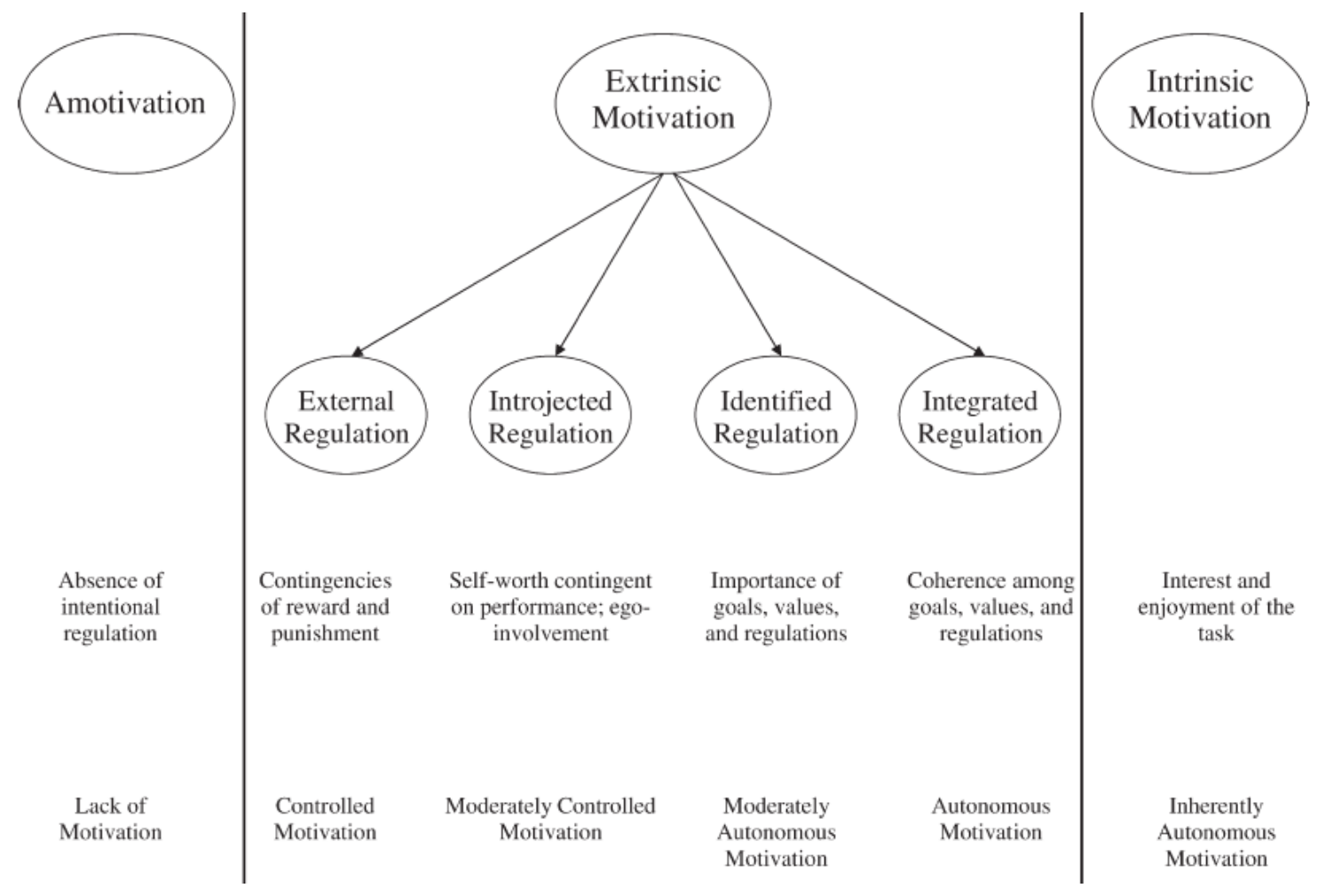

Fundamental to SDT is the argument that extrinsic motivations can be internalised and autonomous. Most theories about internalisation tend to propose internalisation as a dichotomy, such that regulation is either external or internalised. However, SDT proposes that internalisation takes place on a continuum from controlled to autonomous regulation as a way to explain the level to which external regulation has been internalised. Controlled motivation refers to acting with a sense of pressure, while autonomous motivation involves a sense of choice and self-determination (Gagné and Deci 2005). The theory further outlines different forms of autonomous and controlled motivation, which further demonstrates the differences experienced in their underlying and regulatory processes and experiences (Howard et al. 2016).

Two forms of controlled motivation are identified: external regulation and introjected regulation. External regulation is a non-internalised type of extrinsic motivation that occurs when actions are undertaken for external rewards or punishments. In the organisational literature, which is where workplace motivations are mostly explored, external regulation is 
extended to include external social regulation, which is aimed at avoiding (e.g., criticism) or gaining approval and respect from others; and external material regulation, which refers to receiving material rewards (Howard et al. 2016). Introjected regulation is an internalised yet controlled form of extrinsic motivation, where behaviour is aimed at reducing negative feelings like shame, or experiencing positive feelings like pride. Similarly, autonomous motivation consists of identified regulation, which is an internalised form of extrinsic motivation that happens when an individual chooses to respond because the behaviour will be of personal significance; and integrated regulation, which is when coherence is experienced between the activity and the person's personal goals and values. Amotivation is also identified and classified as the lack of a desire to exert any form of effort. This is due to the behaviour not being associated with consequent outcomes, thus the behaviour is performed for unknown reasons or not performed at all (Howard et al. 2016).

SDT remains rooted in the notion that people seek growth. For growth to be achieved, satisfying the needs of competence, relatedness, and autonomy is important for the regulation systems to be internalised; and favourable conditions are required for these to be met (Deci and Ryan 2000).

"Motivation" is energy, direction, and persistence of behaviour (Howard et al. 2016), but remains a complex concept, as is evident from the varying approaches applied to conceptualise and measure it. Early work on motivation includes Vroom's 1964 expectancy-valence theory, and Porter and Lawler's 1968 model of intrinsic and extrinsic work motivation (Gagné and Deci 2005). "Extrinsic motivation" refers to an individual's drive on the basis of an instrumental reason, such as receiving tangible or verbal rewards; while "intrinsic motivation" is driven by an inherent enjoyment a person experiences (Gagné and Deci 2005; Howard et al. 2016). With the emergence of CET, it was argued that external factors (e.g., receiving rewards) tended to diminish people's feelings of autonomy (Amabile, DeJong, and Lepper 1976), and the theory proposed that a focus be applied on either extrinsic or intrinsic motivators, as opposed to on both (Gagné and Deci 2005).

In the context of students enrolled in a sales module at a South African university, different environmental conditions in the form of funding, having to support families, and often living in poverty become an important aspect to acknowledge in order to identify the degree to which these plain requirements are met and the conditions required to allow for the regulatory and internalisation processes to take place. To understand how these challenges are managed, the authors extend their understanding by drawing on boundary theory.

\section{Boundary theory}

Academicians, both qualitative and quantitative, have taken a strong interest in boundary 
management in recent years, which exhibits the work-family relationship (Wepfer et al. 2018). These include (Nippert-Eng's 1996) the seminal author on boundary work, (Clark 2000) with the articulation of border theory, and (Ashforth, Kreiner, and Fugate 2000) with boundary theory. Both the boundary theory (Ashforth et al. 2000) and the border theory (Clark 2000) conceptualise the work and the non-work interaction in terms of boundaries/borders of the different life domains. To balance the demands of the work and non-work environments, individuals continuously create, maintain, and transition across these boundaries/borders (Clark 2000). The intensity of the tactics that individuals use to navigate these work and non-work boundaries fall along a segmentation-integration continuum (Allen, Cho, and Meier 2014; Bulger, Matthews, and Hoffman 2007). A segmentation strategy is typified by strict and impermeable boundaries/borders that disallows for activities, objects, persons, thoughts, and feelings of one domain to enter the other domain. An example here is individuals who separate their work from non-work environments and would not respond to work-related matters after hours, which is considered a non-work environment. Opposite to the segmentation strategy is the integration strategy. An example here is an individual that is more flexible with permeable boundaries that allow for activities, objects, persons, thoughts, and feelings of the work domain to enter the non-work domain and these individuals might bring friends and family members to their workplace. The boundary management approach adds to the existing work-nonwork literature by focusing on individual-level strategies to reconcile the work and nonwork domains. Organisational literature has long acknowledged that work and family are not necessarily separate domains, but rather interdependent with penetrable boundaries. Boundary theory specifically addresses the integration and blurring of work and family life, and is a social classification theory focused on aspects like the meaning that people assign to their home and work, and the ease with which they transition between roles (Wepfer et al. 2018). In the context of this study, the theory is applied to represent family/varying challenges (e.g., working to make money) and study life, and aims to determine whether students apply enacted integration, where they experience relatively weak study/non-study boundaries (flexible, permeable); or enacted segmentation, where they experience strong study/non-study boundaries (inflexible, impermeable) (Peters and Blomme 2019). Which of these two approaches seems most conducive to their success in the module is particularly important.

With the literature background provided above, the continuous scholarly and public debate on burnout, pressure to perform, constant availability and readiness, the onset of the online world and COVID-19 lockdown restriction, the reconcilability of work and non-work life, it is important to recognise how students apply boundary management strategies in relation to their own well-being. The current study seeks to investigate the well-being implications of boundary 
management strategies in the passing of a practical sales module and used the following methodology to find that.

\section{RESEARCH METHODOLOGY}

As this study is exploratory and interpretive in nature, a qualitative approach was used. The data was analysed using inductive content analysis as the researchers wanted to extract meaning and understanding from the text. Inductive content analysis is most appropriate as previous studies on the phenomenon under investigation are scares. The codes and categories were derived directly from the text (Vaismoradi Turunen, and Bondas 2013, 398).

\section{TARGET GROUP AND SAMPLE DECISION}

A purposive sampling technique was used for this study, as it was designed to provide information-rich data for an in-depth study, and the participants had the required status or experience, and were specifically selected as they possess special knowledge to provide the information that the researchers sought (Lopez and Whitehead 2013). In-depth interviews were conducted by an independent research agency to assure anonymity. All forms of identification, such as email addresses, gender, and qualifications, were removed before the interview transcripts were returned to the researchers. The interview protocol was guided by SDT and boundary theory, and contained several open-ended questions to encourage a conversational style interview. The findings of the study were based on information received from eight students who had successfully completed the DSA project. The responses represent a range of students - male and female - at different levels in their qualification. Although more students were invited to the interviews (the target sample was 16), there were many absentees; reasons cited for this included having no money for travel, transport problems, and family issues.

Eight interviews were enough to reach data saturation as repetition become evident after the fifth interview. Fusch and Ness (2015) suggest that data saturation will indicate how many interviews to conduct. Data saturation is accomplished when sufficient information is obtained to replicate the study, when no new information is obtained, and when further coding is no longer feasible. Fusch and Ness (2015) continues and states that data saturation needs to fit the qualitative research approach. Elo et al. $(2014$, p. 8) laments that the trustworthiness of content analysis relies heavy on the availability of rich, appropriate, and well-saturated data, which was obtained in this study. Trustworthiness also depends in the way the data is collected. This study's data was anonymised before it was sent to the researchers and was conducted by an independent researcher. 


\section{RESEARCH ANALYSIS}

This study used the sequential procedural model of inductive content analysis proposed by Mayring $(2014,80)$, This process is outlined below.

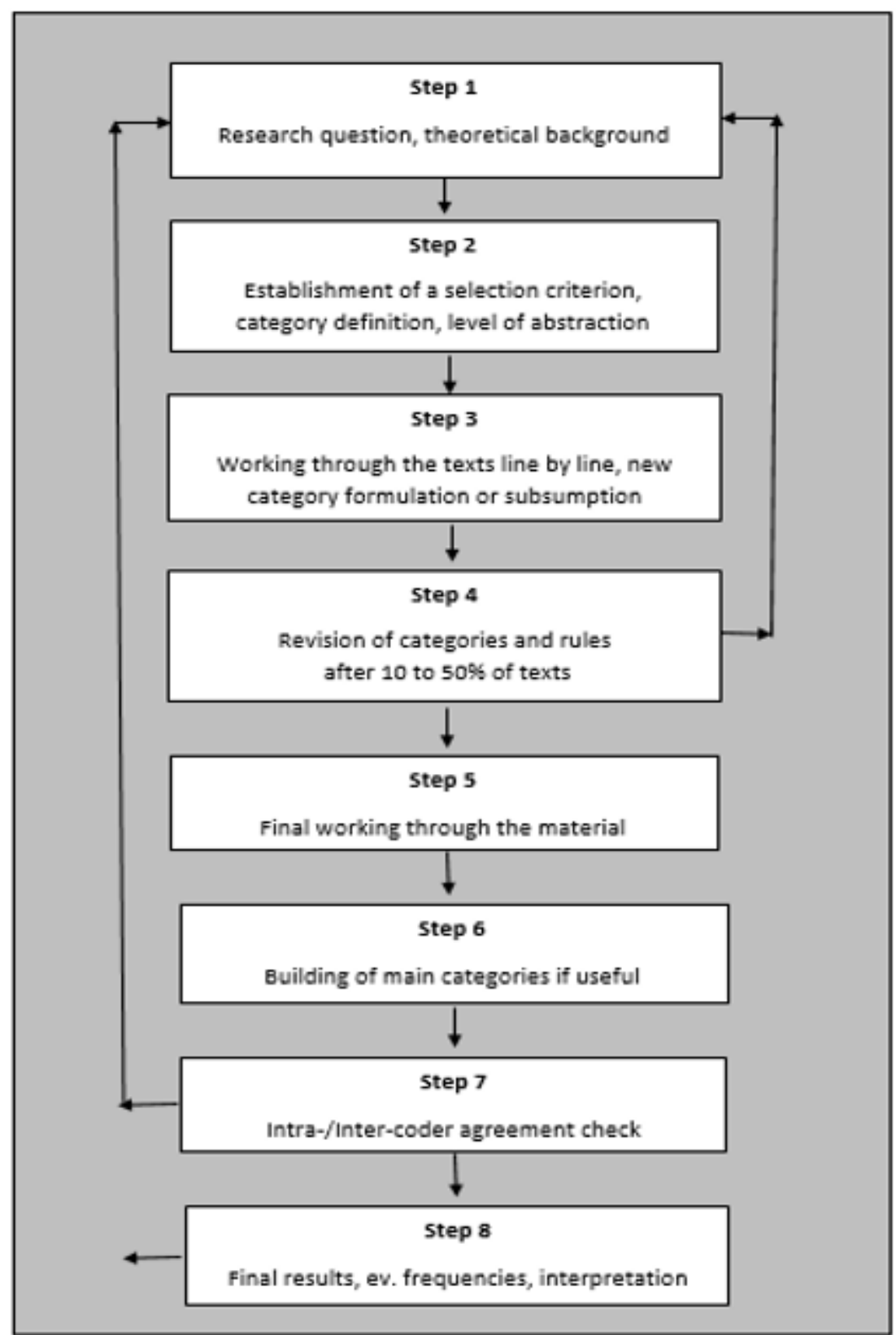

Figure 1: Steps of inductive category management. (Source: Mayring 2014, 80)

\section{Step 1}

Research questions. Create an exploratory research aim with inductive logic in mind. The aim of this study is to understand the daily lives, routines, and challenges of the students enrolled in a specific direct selling module, and what motivates them to pass it. Previous studies and a 
sound literature review must provide the theoretical background of the study. Step 1 is covered in the literature review section.

\section{Step 2}

Category definitions and level of abstraction. Create explicit category definitions which serves as the selection criterion to extract relevant material from the texts. The level of abstraction indicates how specific or general categories have to be defined; this is central to inductive category formation. For the purpose of this study, the specific objectives were operationalised into category definitions. These included: understanding what motivates students to pass the direct selling module by applying the SDT continuum; discovering how students manage their studies and personal responsibilities and challenges while enrolled in this sales module; applying boundary theory, and specifically identifying whether they applied enacted integration or enacted segmentation; and discovering what knowledge the students managed to retain and apply from the module, and whether the acquisition of this knowledge had added value to their lives. Step 2 is covered in the introduction, the literature review, and the respondents' feedback from the interviews.

\section{Step 3}

Coding the text. Qualitative data coding decisions should be guided by the research paradigm and the theoretical approach of the study. In-vivo coding was used to tap into the students' experiences. This is also a method to honour the participant's voice. In-vivo coding is also effective for developing new theories (Saldaña 2009). Steps 3 to 7 were carried out on the interview transcriptions, each time improving on the previous step.

\section{Step 4}

Revision. A revision is done when the category system seems to become stable. This revision is done to check if the category system fits the research aim. If it does not, a rework of the category definitions is necessary. A revision is also done to check if the degree of generalisation is sufficient. If there are only a few categories, then the level of abstraction is too general; and if there are many categories, then the level of abstraction is too specific.

\section{Step 5}

Final coding. All the transcribed interviews have to be checked for category definition and level of abstraction. 


\section{Step 6}

At the end of this process a list of categories emerges. These are grouped together to build themes, that must fit the research aim.

\section{Step 7}

Intra- or inter-coder check. The text is coded from the beginning to match the categories.

\section{Step 8}

Findings. Initially, the findings are the list of categories. A frequency analysis of the categories' occurrence could be useful to determine dominance. The categories and frequencies have to be interpreted in the direction of the research aim. Step 8, revealing the findings of this study, is presented below.

\section{FINDINGS AND DISCUSSION}

The findings were derived from the answers provided in the in-depth interviews and were formulated to reflect the main themes that emerged. All eight participants were anonymised, as it was not the purpose of this study to differentiate on any demographics. Direct quotations were distinguished by referring to the participants as P1 to P8.

When seeking to understand what motivates students to pass the direct selling module by applying the SDT continuum, most of the participants expressed feelings of fear when the DSA project was introduced to them. "I was anxious. I could talk and approach people, but my thing was how am I going to get that specific amount of money in that specific amount of time" (P2).

However, these feelings of fear subsided over time, and positive motivation replaced negative feelings. An interesting finding here is that there was a 50/50 implied split between external regulation and introjected regulation.

"I wanted to go to the mainstream diploma (articulate to a higher qualification), I took it month by month ... I've reached my target, OK I've doubled it somehow, you feel happy" (P1). This quote is an example of external regulation, as the student was motivated to use this module as a tool to reach the next level of the reward to be enrolled for a higher qualification. One motivation was "To reach my sales target" (P4). This is an example of an introjected regulation, as there is an emphasis on self-worth based on performance. From these findings, it is evident that the students applied a more controlled motivation in reaching the set target. At the end of the project, when students were asked, how they felt after completing the project, most expressed feelings of happiness. "It was fulfilling. Regardless of what had happened, it was fulfilling, it was nice" (P4). 
In following SDT, the students' proposed application of controlled motivation suggests that internalisation did not occur, which in turn suggests that the module and tasks did not aid in satisfying the needs of competence, autonomy, and relatedness (Gagné and Deci 2005). From the university's perspective, a great emphasis is placed on the need to pass the module and on the reward of the monies to be earned. This may contribute to the controlled motivation, as it promotes motivation that is rooted in reward and punishment. However, the fact that the students perceived the module as fulfilling suggests there was a sense of accomplishment, but that this was not a driving motivation during the process of completing the module.

To discover how students managed their school and personal responsibilities and challenges while enrolled in this sales module, the research needed to specifically identify whether they applied enacted integration or enacted segmentation. All of the students interviewed applied enacted segmentation - they managed their lives within strict boundaries between study and their personal life, and many even recited their daily schedules down to the last minute:

"My day would start around 5am, I'd start studying until 7am and then take a shower and then come to school. School was an hour away. I'd get there by taxi, I'd go to class and if I had no class, I'd like to head to the library to study some more. That's why I didn't have many friends ... I'd leave campus at 5 , so by 6 I'd be home" (P6).

However, while doing the DSA project, students were always ready to sell. "Yeah, I always had it (sales brochure) on me. People were always asking why are you selling, you could do other things?" (P2). This suggests that an element of enacted integration was applied with this particular module.

The specific schedules and time spent on campus suggested that enacted segmentation was evident, as students clearly distinguished between their life/home and work/school roles (Peters and Blomme 2019). These could be a product of the challenges they experienced, such as travel, funding, and accommodation. Therefore, students could not move freely between places, as this had financial implications, and the distance to travel might have played a role, too (Dell 2018; Nkomo 2015; Strydom 2016; Waghid and Davis 2016).

The enacted integration with the specific module suggests a fairly weak transition and a sense of flexibility between roles (Peters and Blomme 2019). Consequently, students were constantly aware of this challenge and were always ready to take on a sales role. This could have caused a sense of conflict, since students traditionally (in studying other modules) preferred a clear distinction, while this module required them to change their normal preference. Similarly, it could also suggest a positive turn, in that the module forced the students to adapt 
and be flexible.

Concerning the question of what knowledge the students managed to retain and apply from the module, and whether the acquisition of this knowledge added value to their lives, two themes emerged. Most of the students felt that their communication skills and confidence levels had increased: “... if you don't have communication skills, you tend to lack self-esteem. I think one thing is to stand in front of people you don't even know, you have confidence and believe" (P1).

Other themes that emerged were that students' computer skills and financial management improved. An interesting finding to mention here is that no students mentioned that they felt their selling skills improved; they mentioned that only their financial, confidence, communication, and computer-related skills had improved. Furthermore, all of the students were of the opinion that the project should remain part of the curriculum, apart from a few changes that were suggested.

Developing the ability to sell includes a number of proposed skills, although which ones exactly has been heavily debated in literature (Pettijohn, Pettijohn, and Taylor 2007). The fact that students felt that their communication, financial skills, general confidence, and computer skills were developed implies a positive contribution, as particular skills, such as communication and confidence, are acknowledged in literature as being important for successful selling (Pettijohn et al. 2007; Wilson, Strutton, and Farris 2002).

\section{EDUCATOR IMPLICATIONS}

For student motivation to become more internalised and make the learning process more personal and meaningful, a greater emphasis should be placed on developing students' sense of competence, relatedness, and autonomy in this module. Autonomy might be achieved with an emphasis on selling students a vision, rather than merely instructing them to sell. Relatedness might be developed by constantly reminding them that they are not alone in the journey - all of the students are participating together. Competence might be achieved by implementing an even stronger focus on developing student confidence. This might be achieved through a gradual roll-out of targets by starting with small victories - for example, by assigning fewer marks and smaller targets for the first quarter of the year, and then gradually increasing these until students reach the yearly target, rather than setting a large yearly target from the start. Deciding on, and more clearly identifying, exactly what sales skills should be developed to decide what constitutes having developed sales skills is important. Therefore, identifying these skills, and providing specific tasks and preferred outcomes to students to achieve these is recommended. 


\section{THEORETICAL IMPLICATIONS}

This study contributes to the academic knowledge of the type of motivation students in an emerging economy draws on to pass a practical sales module. An emerging economy also has different domestic factors as compared to a developed economy. Hence, it is argued that the students in this economy apply different boundaries to cope with their academic results.

\section{LIMITATIONS AND FUTURE RESEARCH}

Even though the sample reached the saturation point quickly (from six interviews), with the nature of the design being in-depth interviews, a more balanced sample for student performance and marks and gender, and a larger overall sample would have added value. Thus, this is a limitation but, at the same time, an opportunity for future research. A larger sample should also aid in establishing whether the 50/50 split between external regulation and introjected regulation is valid. The identified movement across boundaries, and whether this was beneficial or caused potential conflict also needs further exploration. A longitudinal study engaging again with the students a year or two after having completed the module and having been in the working world is also recommended. This could help to establish the extent to which the module contributed to potential entrepreneurial efforts, or potentially added value in their current employment. It would also be interesting to see whether similar results are obtained if a purely theoretical subject is researched within these theories.

\section{CONCLUSION}

In a country faced with unemployment challenges, the drive to grow entrepreneurship and develop entrepreneurial skills has become important. Sales skills are essential for entrepreneurs and, to address this, a direct selling module is offered at one of South Africa's largest teaching universities. By applying the SDT continuum and boundary theory during in-depth interviews conducted with students enrolled in this module, it was discovered that students were predominantly motivated by controlled forms of motivation, with a 50/50 split between external regulation and introjected regulation. Therefore, the drive to satisfy their needs of competence, autonomy, and relatedness is important to achieve internalised motivation. The students have very rigidly organised lives and tend to plan their lives very meticulously, suggesting a preference for enacted segmentation. However, students realise that to reach their sales targets, they need to always be on standby and ready to sell, suggesting that the module forced them to apply enacted integration. This may have caused conflict in their roles, as this was not the preferred boundary, or it may have contributed positively to developing their abilities to be flexible across boundaries. These role transitions need further exploration. The students also 
mentioned that their confidence as well as their communication, computer, and financial skills developed, with none reporting that they had developed sales skills. This suggests a need to more explicitly define the targeted skills that the module should address, with accompanying strategies and tactical tasks to better develop well-rounded abilities that constitute the development of sales skills.

\section{ETHICAL CLEARANCE}

The proper ethical procedures were followed in line with the university's structures and policies, and an ethical clearance certificate was issued for this study.

\section{REFERENCES}

Allen, T. D., E. Cho, and L. L. Meier. 2014. "Work-family boundary dynamics." Annual Review of Organizational Psychology and Organizational Behavior 1(1): 99-121. doi:10.1146/annurevorgpsych-031413-091330.

Amabile, T. M., W. DeJong, and M. R. Lepper. 1976. "Effects of externally imposed deadlines on subsequent intrinsic motivation." Journal of Personality and Social Psychology 34(1): 92-98.

Anderson, S. J., R. Chandy, and B. Zia. 2018. "Pathways to profits: The impact of marketing vs. finance skills on business performance." Management Science 64(12): 5559-5583.

Ashforth, B. E., G. E. Kreiner, and M. Fugate. 2000. "All in a day's work: Boundaries and micro role transition." Academy of Management Review 25(3): 472-491. doi:10.5465/AMR.2000.3363315.

Aucamp, I. C. 2015. "Social impact assessment as a tool for social development in South Africa: An exploratory study." Doctoral thesis. University of Pretoria, Pretoria. https://repository.up.ac.za/ bitstream/handle/2263/50654/Aucamp_Social_2015.pdf?sequence $=1$.

Bulger, C. A., R. A. Matthews, and M. E. Hoffman. 2007. "Work and personal life boundary management: Boundary strength, work/personal life balance, and the segmentation-integration continuum." Journal of Occupational Health Psychology 12(4): 365-375. doi:10.1037/10768998.12.4.365.

Chimucheka T. 2014. "Entrepreneurship education in South Africa." Mediterranean Journal of Social Sciences 5(2): 403-416.

Clark, S. C. 2000. "Work/family border theory: A new theory of work/family balance." Human Relations 53(6): 747-770.

Deci, E. L. 1971. "Effects of externally mediated rewards on intrinsic motivation." Journal of Personality and Social Psychology 18(1971): 105-115.

Deci, E. L. and R. M. Ryan. 1985. Intrinsic motivation and self-determination in human behavior. New York, NY: Plenum Press.

Deci, E. L. and R. M. Ryan. 2000. "The 'what' and 'why' of goal pursuits: Human needs and the selfdetermination of behavior." Psychological Inquiry 11(4): 227-268.

Dell, S. 2018. "Meeting basic needs - A first step to student success.: University World News June 22. https://www.universityworldnews.com/post.php?story=20180622154430588.

Direct Selling Association of South Africa. 2020. Direct Selling Association of South Africa. http://www.dsasa.co.za/modules fe/layout2/default.asp

Dison, L., Y. Shalem, and D. Langsford. 2019. "Resourcefulness matters: Student patterns for coping with structural and academic challenges." South African Journal of Higher Education 33(4): 7693. 
Dominguez-Whitehead, Y. 2017. "Food and housing challenges: (Re)framing exclusion in higher education." Journal of Education 68: 149-169.

DSA see Direct Selling Association.

EDHE see Entrepreneurship Development in Higher Education.

Elo, S., M. Kääriäinen, O. Kanste, T. Pölkki, K. Utriainen, and H. Kyngäs. 2014. "Qualitative content analysis: A focus on trustworthiness." Sage Open 4(1): 1-10.

Entrepreneurship Development in Higher Education. 2018. Entrepreneurship Development in Higher Education 2018 Lekgotla. http://www.dhet.gov.za/SiteAssets/Minister\%20Speech\%202018/ Entrepreneurship\%20Development\%20in\%20Higher\%20Education\%202018\%20Lekgotla.pdf.

Forbes Coaches Council. 2018. "11 skills every entrepreneur needs to up their sales game." Forbes February 22. https://www.forbes.com/sites/forbescoachescouncil/2018/02/22/11-skills-everyentrepreneur-needs-to-up-their-sales-game/\#667a892f3a9c.

Fusch, P. I. and L. R. Ness. 2015. "Are we there yet? Data saturation in qualitative research." The Qualitative Report 20(9): 1408-1416.

Gagné, M. and E. L. Deci. 2005. "Self-determination theory and work behaviour." Journal of Organizational Behavior 26(4): 331-362.

Hornsby, D. J. 2015. "How South African universities are governed is the biggest challenge." The Conversation September $8 . \mathrm{https} / / /$ theconversation.com/how-south-african-universities-aregoverned-is-the-biggest-challenge-47075.

Howard, J., M. Gagné, A. J. S. Morin, and A. Van den Broeck. 2016. "Motivation profiles at work: A self-determination theory approach.” Journal of Vocational Behavior 95-96: 74-89.

Lepper, M. R., D. Greene, and R. E. Nisbett. 1973. "Undermining children's intrinsic interest with extrinsic reward: A test of the 'overjustification' hypothesis." Journal of Personality and Social Psychology 28(1): 129-137.

Lopez, V. and D. Whitehead. 2013. "Sampling data and data collection in qualitative research." In Nursing and midwifery research: Methods and appraisal for evidence based practice, ed. Z. Schneider, D. Whitehead, G. LoBiondo-Wood, and J. Haber, 123-140. $4^{\text {th }}$ Edition. Sydney: Elserivier. https://www.academia.edu/25502575/.

Mabelebele, J. 2015. HE in South Africa: Emerging challenges and implications for universities. https://www.pwc.co.za/en/assets/pdf/he-conference_the-future-of-higher-education-in-southafrica.pdf.

Malele, I. 2011. Access to higher education: Challenges: Higher Education SA briefing. https://pmg.org.za/committee-meeting/12495/.

Mayring, P. 2014. Qualitative content analysis: Theoretical foundation, basic procedures and software solution. https://www.ssoar.info/ssoar/handle/document/39517.

Mushemeza, E. D. 2016. "Opportunities and challenges of academic staff in higher education in Africa." International Journal of Higher Education 5(3): 236-246.

Nippert-Eng, C. 1996. "Calendars and keys: The classification of 'home' and 'work'." Sociological Forum 11(3): 563-583. doi:10.1007/BF02408393.

Nkomo, S. M. 2015. "Challenges for management and business education in a 'developmental' state: The case of South Africa." Academy of Management Learning \& Education 14(2): 242-258.

Peters, P. and R. J. Blomme. 2019. "Forget about the 'ideal worker': A theoretical contribution to the debate on flexible workplace designs, work/life conflict, and opportunities for gender equality." Business Horizons 62(5): 603-613.

Pettijohn, C. E., L. S. Pettijohn, and A. J. Taylor. 2007. "Does salesperson perception of the importance of sales skills improve sales performance, customer orientation, job satisfaction, and organizational commitment, and reduce turnover?" Journal of Personal Selling \& Sales Management 252(1): 75-88. 
Radipere, S. 2012. "South African university entrepreneurship education." African Journal of Business Management 6(44): 11015-11022.

Saldaña, J. 2009. The coding manual for qualitative researchers. London: Sage.

Schrank, H. 2006. Border and boundary theory: A concept paper for NC 1030. http://www.montana. edu/extensionecon/nc1030/Concept-Papers/borderandboundarytheory.doc.

StatsSA. 2019. Unemployment rises slightly in third quarter 2019. October 29. http://www.statssa.gov.za/?p=12689.

Strydom, B. 2016. "South African university history: A historiographical overview." African Historical Review 48(1): 56-82.

Urban, B. 2018. Entrepreneurship is on the agenda again: More hype or real action? April 10. https:/www.wits.ac.za/news/latest-news/in-their-own-words/2018/2018-04/entrepreneurship-ison-the-agenda-again-more-hype-or-real-action.html.

Vaismoradi, M., H. Turunen, and T. Bondas. 2013. "Content analysis and thematic analysis: Implications for conducting a qualitative descriptive study." Nursing and Health Sciences 15(3): 398-405.

Waghid, Y. and N. Davis. 2016. "Educational leadership as action: Towards an opening of rhythm." South African Journal of Higher Education 30(1): 123-137.

Walwyn, D. 2016. "Universities are becoming major players in the national system of innovation." South African Journal of Science 112(7/8): 1-8.

Wepfer, A. G., T. D. Allen, R. Brauchli, G. J. Jenny, and G. F. Bauer. 2018. "Work-life boundaries and well-being: Does work-to-life integration impair well-being through lack of recovery?" Journal of Business and Psychology 33(6): 727-740. doi:10.1007/s10869-017-9520-y.

Wilson, P. H., D. Strutton, and M. T. Farris, II. 2002. "Investigating the perceptual aspect of sales training." Journal of Personal Selling \& Sales Management 22(2): 77-86. 